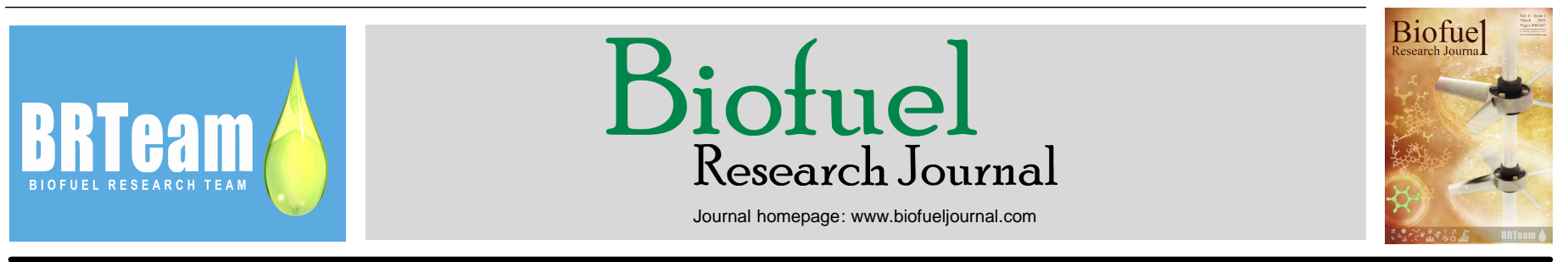

Original Research Paper

\title{
Trilateral correlation of spray characteristics, combustion parameters, and deposit formation in the injector hole of a diesel engine running on preheated Jatropha oil and fossil diesel fuel
}

\author{
Anh Tuan Hoang ${ }^{1,2, *}$, Anh Tuan Le ${ }^{3}$ \\ ${ }^{1}$ Ho Chi Minh city University of Transport, Ho Chi Minh, Vietnam. \\ ${ }^{2}$ Ho Chi Minh city University of Technology (HUTECH), Ho Chi Minh, Vietnam. \\ ${ }^{3}$ Hanoi University of Science and Technology, Hanoi, Vietnam.
}

\section{HIGHLIGHTS}

$>$ Preheated and unpreheated straight Jatropha oil, and fossil diesel fuel were experimentally compared. $>$ Spray characteristics, i.e., cone angle and penetration length were investigated. $>$ Thermal efficiency and emission parameters were tested at $0 \mathrm{~h}$ and after $300 \mathrm{~h}$ of engine operation. $>$ Trilateral correlation of spray characteristics, combustion parameters, and deposit accumulation in injector orifices was analyzed.

> Unpreheated straight Jatropha oil cannot be recommended for long term use in diesel engines.

\section{GRAPHICAL ABSTRACT}

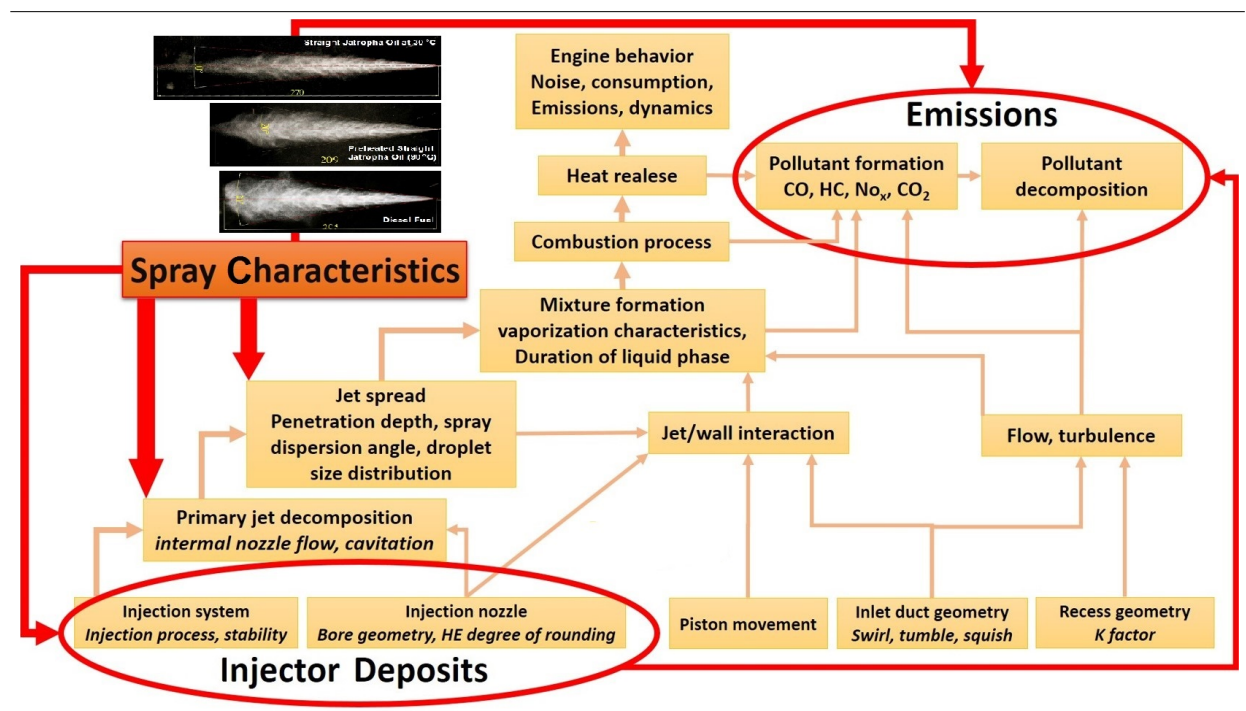

\section{Article history:}

Received 21 October 2018

Received in revised form 11 December 2018

Accepted 11 December 2018

Available online 1 March 2019

\section{Keywords:}

Preheated Jatropha oil

Endurance test

Spray characteristics

Injector

Deposit formation

Thermal efficiency

Emissions

\section{ARTICLE INFO}

\begin{abstract}
The long term use of pure vegetable oil in diesel engines should be thoroughly evaluated from different perspectives including engine performance, deposit formation, etc. to ensure its compatibility. In line with that, the trilateral correlation of spray characteristics, combustion parameters, and deposit formation in the injector hole of a high-speed, 4-stroke, direct injection diesel engine fueled with pure Jatropha oil and diesel fuel (DF) was studied. Jatropha oil was investogated at room temperature $30^{\circ} \mathrm{C}$ (SJO30) and in preheated form at $90^{\circ} \mathrm{C}$ (PSJO90). The expertimental tests were conducted in two phases: (i)- investigation of the spray characteristics of the fuels including cone angle and penetration length at 200 bar of injection pressure, (ii)investigation of the combustion characteristics (i.e., thermal efficiency and engine emissions) and deposits formation in the injector hole of the diesel engine at $0 \mathrm{~h}$ and $300 \mathrm{~h}$ of operation. The results obtained showed large differences between the spray characteristics of SJO30 and the other fuels investigated. Moreover, this fuel led to significant reductions in NOx emissions $(14.69-20.30 \%)$ and thermal efficiency (3.04-4.41\%) but large increases in CO emissions (26.36-77.57\%), HC emissions (48.98$77.85 \%$ ), and smoke (58.43-131.71\%). It also resulted in huge deposits formed in the injector hole after $300 \mathrm{~h}$ of the endurance test compared to DF and PSJO90 as revealed by optical observations using scanning electron microscopy analysis. Overall and compared to DF, SJO30 cannot be recommended for long term use in diesel engines while preheating or in better words, PSJO90 may only be considered as an alternative fuel in the short term.
\end{abstract}

(c) 2019 BRTeam. All rights reserved.

* Corresponding author at: Tel.: +84-904317584

E-mail address: anhtuanhoang1980@gmail.com ; tuan.hoang@ut.edu.vn

Please cite this article as: Hoang A.T., Le A.T. Trilateral correlation of spray characteristics, combustion parameters, and deposit formation in the injector hole of a diesel engine running on preheated Jatropha oil and fossil diesel fuel. Biofuel Research Journal 21 (2019) 909-919. DOI: 10.18331/BRJ2019.6.1.2 


\begin{tabular}{|ll|}
\hline Abbreviations & \\
$\mathrm{BSFC}$ & Brake specific fuel consumption \\
$\mathrm{CN}$ & Cetane number \\
$\mathrm{CP}$ & Cloud point \\
$\mathrm{DF}$ & Diesel fuel \\
$\mathrm{HC}$ & Unburnt hydrocarbon \\
$\mathrm{HHV}$ & Higher heating value \\
$\mathrm{LHV}$ & Lower heating value \\
$\mathrm{L}_{\mathrm{l}}$ & Length of liquid \\
$\mathrm{L}_{\mathrm{f}}$ & Flame lift-off \\
$\mathrm{M}$ & Fuel mas \\
$\mathrm{NO}$ & Nitrogen oxide \\
$\mathrm{PAH}$ & Polycyclic aromatic hydrocarbon \\
$\mathrm{PM}$ & Particulate matter \\
$\mathrm{PSJO}$ & Preheated straight Jatropha oil \\
$\mathrm{SEM}$ & Scanning electron microscope \\
$\mathrm{SJO}$ & Straight Jatropha oil \\
$\eta_{\mathrm{e}}$ & Thermal efficiency \\
\hline
\end{tabular}

\section{Introduction}

Growing environmental pollution and the consequent impacts on human health necessitate more dedicated efforts to increase the market share of non/less polluting alternative fuels in the transportation sector. This becomes even more important given the exponential expansion of the transportation means and the resultant per capita energy consumption since the industrial revolution (Hoang, 2018a; Kumar et al., 2018). In line with that, green energy carriers including biofuels or environmentally friendly processes/innovations such as waste heat recovery, exhaust treatment technology, and hybrid engines have been considered as strategies to address these challenges (Demirbas, 2017; Hoang, 2018b; Littlejohns et al., 2018). Biofuels could not only play an important part in satisfying the stringent emissions regulations but also could meet the energy and technical requirements of the existing engines (Cazarolli et al., 2016; Rajaeifar et al., 2017; Hoang and Pham, 2018a).

Among various types of biofueks, bio-oils have received a considerable deal of attention mainly due to the availability of feedstocks (Olarte et al., 2016; Rogers and Zheng, 2016). Moreover, straight vegetable oils` heat content and cetane number are insignificantly lower than those of traditional diesel fuel and they are therefore suitable for use in unmodified diesel engines (Manchanda et al., 2018). However, higher molecular mass resulting in higher density, and higher molecular-linking force leading to higher surface tension and kinematic viscosity compared to traditional diesel fuel are considered as the main cause of low volatilization, poor atomization, heterogeneous mixture, and incomplete combustion, which could adversly affect engine performance and the formation of deposits on the surface of components of the combustion chamber (Salehi Jouzani et al., 2018; Pham et al., 2018). Observations of the deposit formation on the injector (noses, needle, and holes), the combustion chamber wall, cylinder head, and the piston (crown and groove) under certain operating conditions of diesel engines fueled with vegetable oils were reported in numerous studies (Satyanarayana and Muraleedharan, 2012; Hoang and Pham, 2018b). More specifically, deposits are initially formed on injector noses because injector noses are indicated as the lowest-temperature region of the combustion chamber. The intensity of the formed deposits on injector noses is strongly affected by injector configuration, diesel engine type, vegetable oil quality, and how the straight vegetable oils are used. As reported in the published literature, vegetable oils supplemented by additives or preheated showed lower deposits formation than the cases of no-additives or without being preheated (Hoang and Pham, 2019).

There are many hypotheses trying to explain the formation of deposits on the basis of the physicochemical properties of vegetable oils. Reddy et al. (2016) experimentally evaluated the influence of Karanja and Jatropha oilbased fuels on deposit formation and weight loss (due to the wear) on some critical components of fuel injection equipment of a diesel engine such as plunger, nozzle, needle, and valve holder, at $7.4 \mathrm{~kW}$ of rated power and 1500 rpm during $250 \mathrm{~h}$ of operation. The increase in wear and deposits for the abovementioned components of the test diesel engine fueled with Karanja and
Jatropha oil-based fuels were reported. In another study, Li et al. (2010) set out to study the impact of using vegetable oil on fuel injector deposits. An in-line Perkins Phaser 180Ti diesel engine with 6 cylinders was used. Even short periods of the diesel engine operation running on vegetable oil were associated with significant changes in emissions as well as deposit formation around the injector tip (approx. $400 \mu \mathrm{m}$ thick deposits formed in the nozzle holes). Similar results were also reported by D'Alessandro et al. (2016) and Barker et al. (2011). Such high deposits formation by vegetable oils could be attributed to their high viscosity resulting in large cone angle and high spray penetration. Such adverse spray characteristics along with their triglycerides content could cause the adhesion of unburnt substances onto the injector parts (Hoang and Le, 2019).

It should also be noted that deposits could result in changes in the shape of the injector as well such as reduction of injector hole diameter and fuel mass as well as reduction of the injector`s capacity of heat transfer (Birgel et al., 2012; Lefebvre and Mcdonell, 2017). These could consequently lead to power loss, reduction of thermal efficiency, and increases in emissions. In a study by Rakopoulos et al. (2014), operation of a high-speed direct injection diesel engine fueled with vegetable oil resulted in power loss, reduction of thermal efficiency, and increased $\mathrm{CO}, \mathrm{HC}$, and soot emissions. On the contrary, complete oxidation products such as $\mathrm{CO}_{2}$ and $\mathrm{NO}_{2}$ were decreased. Similar changes in emissions in response to the application of vegetable oil were documented by other studies as well (Pipitone and Costanza, 2018).

Obviously, deposit formation in the injector could be a key link in the core correlation of various parameters including fuel properties, spray characteristics, vaporization and mixing, as well as combustion and engine performance. In line with that, more in-depth insights into the interwoven relationship among spray characteristic, deposit formation on the injector, and emission parameters of diesel engines fueled with vegetable oil need to be acquired. Therefore, this study was aimed at evaluating the fuel spray characteristics, deposit formation on the injector, and its impacts on brake specific fuel consumption (BSFC), thermal efficiency, and emissions of a diesel engine after long-term engine operation, i.e., $300 \mathrm{~h}$.

\section{Materials and Methods}

\subsection{Materials}

In this experimental work, non-edible straight Jatropha oil (SJO), extracted from Jatropha curcas $L$. seed available in Vietnam was used. The oil was provided by Minh Hoang Gia Lai Corporation, whereas diesel fuel was provided by Petrovietnam group. Table 1 presenta the physicochemical properties of Jatropha oil and diesel fuel (DF).

Table 1.

Physicochemical properties of Jatropha oil and diesel fuel at $30{ }^{\circ} \mathrm{C}$.

\begin{tabular}{lllll}
\hline \multirow{2}{*}{ Properties } & Unit & ASTM standard & \multicolumn{2}{c}{ Fuels } \\
\cline { 4 - 5 } & & & Jatropha oil & Diesel fuel \\
\hline Density & $\mathrm{g} / \mathrm{cm}^{3}$ & $\mathrm{D} 1298$ & 0.911 & 0.850 \\
Kinematic viscosity & $\mathrm{mm}^{2} / \mathrm{s}$ & $\mathrm{D} 445$ & 31.4 & 3.2 \\
Surface tension & $\mathrm{mN} / \mathrm{m}$ & $\mathrm{D} 971$ & 30.6 & 25.8 \\
Flash point & ${ }^{\circ} \mathrm{C}$ & $\mathrm{D} 93$ & 229 & 71 \\
Cetane number & & $\mathrm{D} 976$ & 41 & 45 \\
Higher heating value & $\mathrm{MJ} / \mathrm{kg}$ & $\mathrm{D} 240$ & 40 & 46 \\
Ash content & $\%$ & D482-91 & $0.002-0.03$ & $0.006-0.1$ \\
Carbon mass & $\%$ & E777 - 17a & $73-77.6$ & $83.5-87$ \\
Hydrogen mass & $\%$ & E777 - 17a & $11.6-12.3$ & $11.5-14$ \\
Oxygen mass & $\%$ & D7607M - 11e1 & $10.8-12.5$ & 0 \\
\hline
\end{tabular}

It can be clearly seen from Table 1 , cetane number $(\mathrm{CN})$ and higher heating value (HHV) of Jatropha oil were approximately $10 \%$ lower than those of DF. On the contrary, three physical properties of Jatropha oil including density, kinematic viscosity, and surface tension were much 
higher than those of DF. The presence of oxygen could be regarded as a highlighted advantage of Jatropha oil compared to DF.

\subsection{Fuel processing and fuel types}

Heating method was considered to improve the disadvantages associated with the application of Jatropha oil, such as high density, high kinematic viscosity, and surface tension. More specifically, Jatropha oil was preheated by electrical energy and a thermal sensor was used to control the heating temperature. The density, kinematic viscosity, and surface tension of Jatropha oil were respectively $0.854 \mathrm{~g} / \mathrm{cm}^{3}, 3.5 \mathrm{~mm}^{2} / \mathrm{s}$, and $26.2 \mathrm{mN} / \mathrm{m}$ after preheating at $90^{\circ} \mathrm{C}$ in comparison with $0.850 \mathrm{~g} / \mathrm{cm}^{3}, 3.2 \mathrm{~mm}^{2} / \mathrm{s}$, and $25.8 \mathrm{mN} / \mathrm{m}$ recorded for for $\mathrm{DF}$ at room temperature (i.e, $30{ }^{\circ} \mathrm{C}$ ). Thus, the above-mentioned preheating temperature value (i.e., $90^{\circ} \mathrm{C}$ ) was used to process SJO (PSJO90). To evaluate thoroughly, different fuel types, i.e., SJO at room temperature (SJO30), PSJO90, and DF were used in the diesel engine experiments.

Moreover, the thermal efficiency $\left(\eta_{\mathrm{e}}\right)$ of the investigated diesel engine was calculated via lower heating value ( $\mathrm{LHV}, \mathrm{kJ} / \mathrm{kg})$ or $\mathrm{HHV}(\mathrm{kJ} / \mathrm{kg})$ as well as BSFC (g/kW.h) following Equation 1 (Hoang and Nguyen, 2017):

$\eta_{e}=\frac{N_{e}}{1000 \cdot(M) \cdot(L H V)}=\frac{3600}{(B S F C) \cdot(L H V)}=\frac{3600}{(B S F C) \cdot(H H V-3 \cdot 052)} \quad$ Eq. 1

where $\mathrm{N}_{\mathrm{e}}$ stands for rated power $(\mathrm{kW})$ and $\mathrm{M}$ denotes mass flowrate $(\mathrm{kg} / \mathrm{h})$.

\section{Experimental setup and analytical procedures}

A high-speed direct injection Yanmar TF120M diesel engine was used in the experiments. The technical specifications of the engine is tabulated in Table 2 .

Table 2.

Technical specifications of the high-speed, direct injection, 4-stroke, 4 -cylinder, cooled-water Yanmar TF120M diesel engine used in this study.

\begin{tabular}{lll}
\hline Technical parameters & Description \\
\hline Displacement & $638.1 \mathrm{~cm}^{3}$ \\
Bore/ Stroke & $92 \mathrm{~mm} \times 96 \mathrm{~mm}$ \\
Compression ratio & $17.7: 1$ \\
Rated power & & $7.8 \mathrm{~kW}$ at $2400 \mathrm{rpm}$ \\
\cline { 2 - 3 } & timing & 11.5 degree BTDC \\
& pressure & $200 \mathrm{bar}$ \\
Injection & hole diameter & $0.26 \mathrm{~mm}$ \\
& angle & $150 \mathrm{degree}$ \\
\hline
\end{tabular}

The analytical procedures used were as follows:

- Spray characteristics of the fuels were determined under the ambient temperature and pressure by the assistance of a mechanical system that coupled with a high-speed Sony A9 camera and a heating system. Sony A9 is a Mirrorless camera with a sensor 24MP Full Frame, a shutter speed of 20fps (frames/s), a well-matched autofocus system with 693-point phase-detection covering $93 \%$ of the image area, and a $3.686 \mathrm{~m}$-dot resolution. A mechanical fuel injector with a delivery valve opening under a pressure of 200 bar (equal to the injection pressure of the Yanmar TF120M diesel engine) was used. The spray characteristics were investigated at room temperature $\left(30^{\circ} \mathrm{C}\right)$ for both Jatropha oil and $\mathrm{DF}$, and at $90{ }^{\circ} \mathrm{C}$ for Jatropha oil. The schematic presentation of the test setup used for this purpose is presented in Figure1.

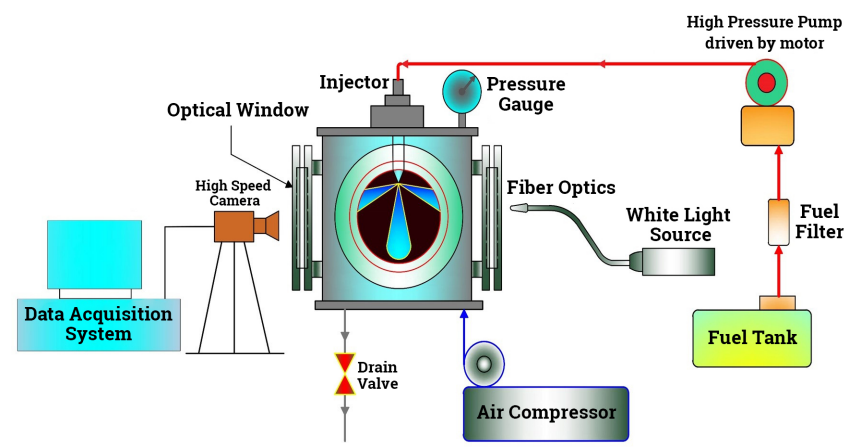

Fig. 1. Schematic presentation of the experimental setup used to test fuel spray characteristics.

- $\quad$ BSFC and emission parameters were measured at $100 \%$ load and at different engine speeds of 1200, 1400, 1600, 1700, 1800, 2000, 2200, and $2400 \mathrm{rpm}$. These measurements were conducted at the first hour $(0 \mathrm{~h})$ and at $300 \mathrm{~h}$ of operating time. The diagram of the experimental setup used to carry out the engine tests and the instruments used are shown in Figure 2 and Table 3, respectively. The emission characteristics were recorded by a CEB-II cabinet exhaust gas analyzer. The accuracy of the measurements including emissions (HC, CO, NOx, and smoke) are presented in Table 4.

Table 3.

Instruments used in the engine tests.

\begin{tabular}{lcccccc}
\hline Parameters & \multirow{2}{*}{$\begin{array}{c}\text { Speed } \\
(\mathbf{r p m})\end{array}$} & $\begin{array}{c}\text { BSFC } \\
(\boldsymbol{\%})\end{array}$ & \begin{tabular}{c} 
HC \\
\cline { 5 - 7 }
\end{tabular} & $\begin{array}{c}\mathbf{C O} \\
(\mathbf{p p m})\end{array}$ & $\begin{array}{c}\text { NOx } \\
(\mathbf{p p m})\end{array}$ & $\begin{array}{c}\text { Smoke } \\
(\boldsymbol{\%})\end{array}$ \\
\hline Accuracy & \pm 5 & \pm 2 & \pm 1 & \pm 3 & \pm 5 & \pm 0.1 \\
\hline
\end{tabular}

Table 4.

Accuracy of the measurements.

\begin{tabular}{ll}
\hline Instrumentation & Working parameter \\
\hline Electric brake, APA100 & Rated power 200kW \\
Cooling device, AVL553 & Electric and Pneumatic \\
Cooling lubrication oil, AVL554 & Electric and Pneumatic \\
Fuel controller, THA100 & Automatic \\
Fuel balance, 733S & Sensor \\
Combustion Emission Bench, CEB-II & Automatic \\
\hline
\end{tabular}

- Deposit accumulation measurements in the injector were carried out after $300 \mathrm{~h}$ of engine operation at $2400 \mathrm{rpm}$ of engine speed. Deposits in the injector were examined with the assistance of Scanning Electron Microscopy (SEM). The results are averages of three times of measurement.

\section{Results and Discussion}

\subsection{Spray characteristics}

Spray characteristics including cone angle and penetration length are considered as the key parameters affecting the combustion process 


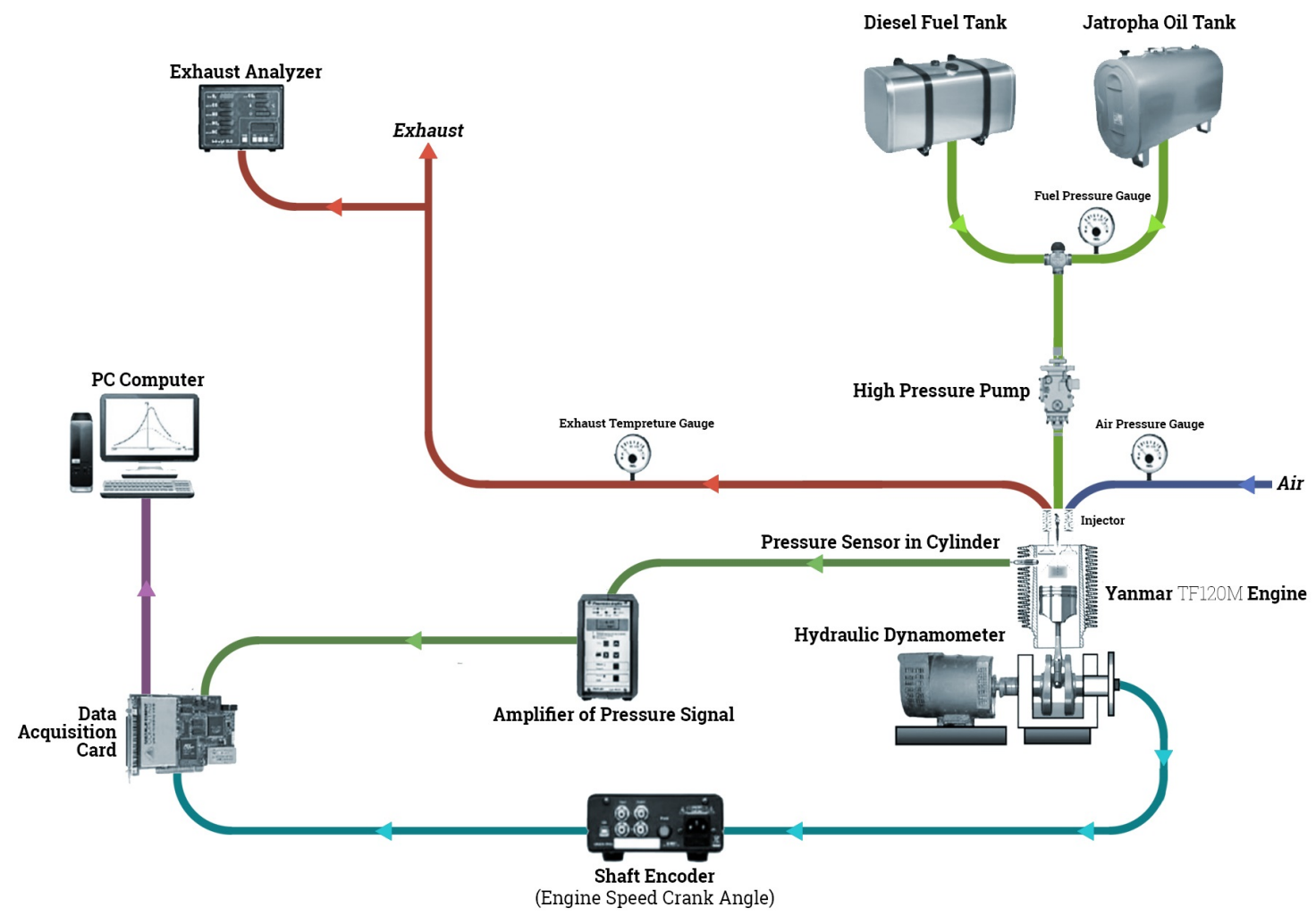

Fig. 2. Experimental Yanmar TF120M diesel engine setup used in the present study.

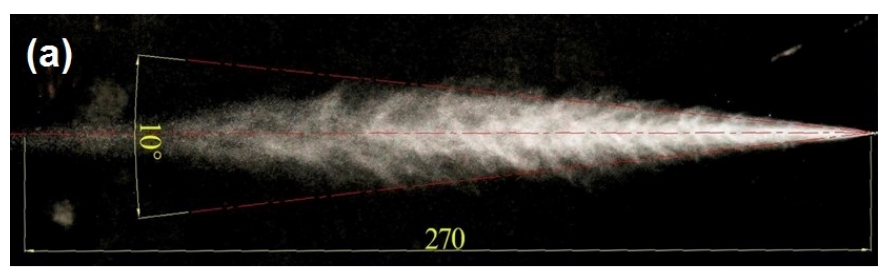

(b)

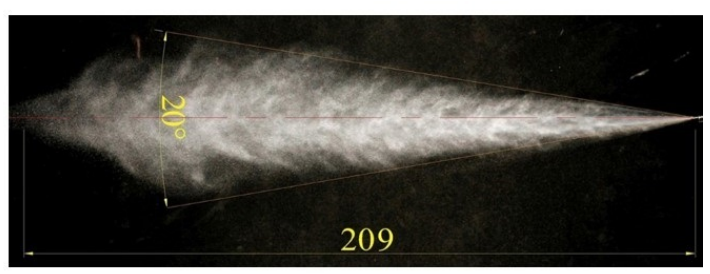

(c)

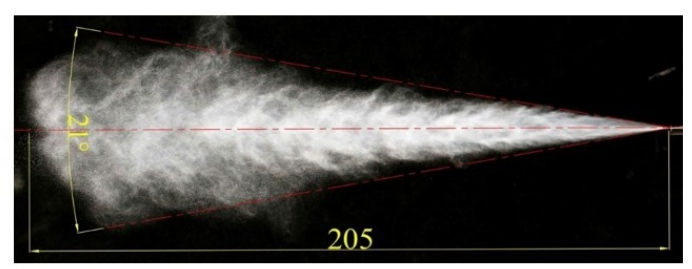

Fig. 3. Spray characteristics of various fuels tested; (a) straight Jatropha oil at $30^{\circ} \mathrm{C}$ (SJO30), (b) straight Jatropha oil at $90{ }^{\circ} \mathrm{C}$ (PSJO90), and (c) diesel fuel (DF).

primarily. On this basis, injection strategies aiming at obtaining maximal energy output from the combustion process of fuel-air mixtures must be controlled and improved so that the emissions produced as well as the deposits formed would be minimized. The spray characteristics of SJO30, PSJO90, and DF at $30{ }^{\circ} \mathrm{C}$ are shown in Figure 3 .

Jatropha oil has a higher density, kinematic viscosity, and higher surface tension compared to DF at the same temperature of $30{ }^{\circ} \mathrm{C}$. It can be seen clearly from Figure 3 that at $30^{\circ} \mathrm{C}$, cone angle for Jatropha oil was small, corresponding to 10 degrees compared to 21 degrees for DF (Figs. 3a and c). On the contrary, the penetration length for Jatropha oil at $30{ }^{\circ} \mathrm{C}$ was large, corresponding to $270 \mathrm{~mm}$, compared to $205 \mathrm{~mm}$ for DF (Figs. 3a and c). However, by increasing the heating temperature to $90{ }^{\circ} \mathrm{C}$, the reduction of density, kinematic viscosity, and surface tension of Jatropha oil led to similar spray characteristics between Jatropha oil and DF. As a result, the cone angle for Jatropha oil increased by 10 to 20 degrees while the penetration length was reduced by $60 \mathrm{~mm}$ degree reaching $209 \mathrm{~mm}$ (Fig. 3b). Overall, insignificant differences were observed between PSJO90 and $\mathrm{DF}$ in terms of cone angle and penetration length.

The influence of fuel spray characteristics on fuel-air mixture formation and its combustion characteristics has been reported in the published literature (Lefebvre et al., 2017). Following the commencement of the fuel injection process, fuel droplets are promptly introduced into the combustion chamber where they tend to break into smaller droplets owing to high temperatures, high pressures, and the air disturbance during fuel injection. The distribution of fuel droplet size is much influenced by the abovementioned three properties of the fuel, i.e., density, kinematic viscosity, and surface tension. In the case of fuels with low kinematic viscosity and density, the intra-molecular force called Van-der-Waals forces is small and the low surface tension results in increasing evaporation rates and consequently, shorter times for breakup and mixing (Deshmukh et al., 2012). Compared to PSJO90 and DF, the kinematic viscosity of SJO30 was around 10 times higher, while its density and surface tension were $10.72 \%$ and $11.86 \%$ higher, respectively. Therefore, there was insufficient time for the vaporization process of SJO30. In fact, in the case of Yanmar TF120M diesel engine with $11.5^{\circ} \mathrm{BTDC}$ of injection timing, the time for the piston

Please cite this article as: Hoang A.T., Le A.T. Trilateral correlation of spray characteristics, combustion parameters, and deposit formation in the injector hole of a diesel engine running on preheated Jatropha oil and fossil diesel fuel. Biofuel Research Journal 21 (2019) 909-919. DOI: 10.18331/BRJ2019.6.1.2 
moving to TDC is around $790 \mu \mathrm{s}$ at $2400 \mathrm{rpm}$ of engine speed. Such short time would not be sufficient for SJO30 droplets with such high viscosity and surface tension to turn into vapor completely. Thus, a poor mixture of SJO30 vapor and air would be created. Moreover, injection velocity of SJO30 fuel must have decreased due to its high viscosity and fuel mass for similar volume of fuel injected at each time of injection must have increased due to its high density. Based on the theory proposed by Lefebvre et al. (2017), low injection velocity, as in the case of SJO30, could lead to a low Reynolds number and a high Ohnesorge number. Thus, the Rayleigh regime in fuel spray characteristics must have occured in case of SJO30. The primary breakup process based on the Rayleigh regime produce fuel droplets of large sizes (Deshmukh et al., 2012). As reported by Baumgarten (2006), the primary breakup process plays an extremely important role in the evaporation, mixing, and combustion processes of fuels. Different mechanisms for primary breakup process of fuel generating fuel droplets are presented in Figure 4 (Som and Aggarwal, 2010).

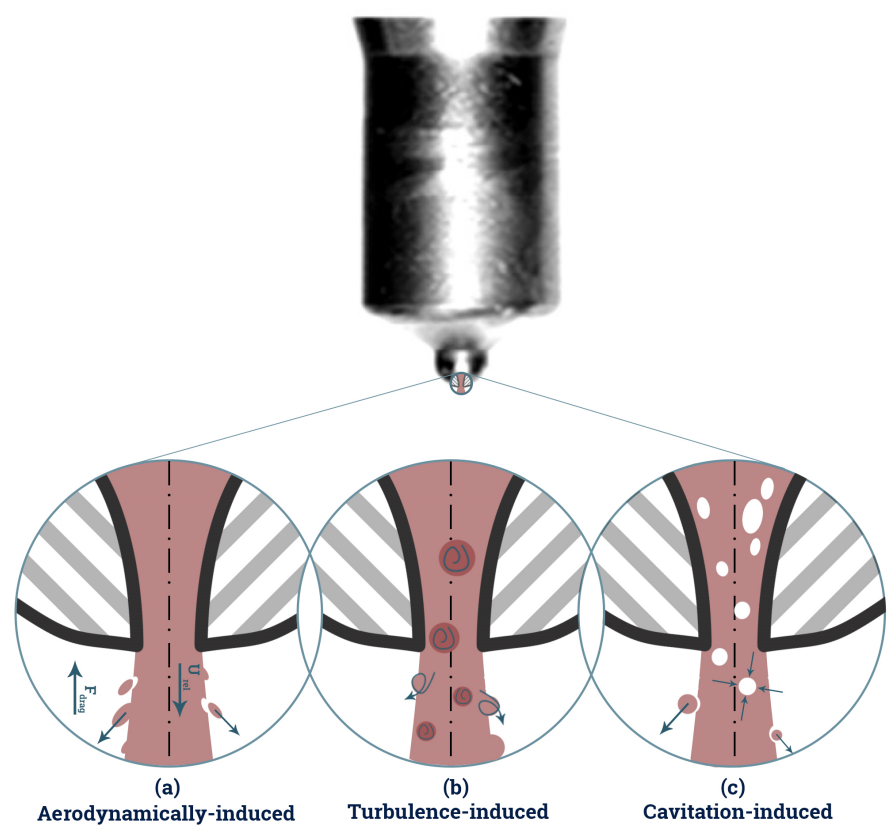

Fig. 4. Schematic presentation of different mechanisms for primary breakup process of fuel and the generation of fuel droplets: (a) aerodynamically induced, (b) turbulence induced, and (c) cavitation induced. Adopted from Som and Aggarwal (2010).

As shown in Figure 4a (aerodynamically-induced), it can be understood that the aerodynamically-induced breakup process occurs if the linking force among fuel molecules is so great that the turbulence of air in the combustion chamber and the turbulence of liquid fuel passing through the injector holes are not large enough to break the fuel droplets. In the case of SJO30, very high kinematic viscosity as well high surface tension and density must have resulted in difficulties in break-up and evaporation of fuel particles under such engine conditions. Thus, most of the SJO30 droplets must have been generated aerodynamically following fuel injection and hitting the cylinder wall surface while some must have been generated through turbulence (Fig. $4 \mathrm{~b}$ ). As a result, large amounts of SJO30 droplets could not be burnt or were only burnt outside the surface layer rather than the core of the droplets. This could be considered as the main cause of the increase in deposits and unburnt emissions, the reduction of thermal efficiency which will be presented and discussed in the subsequent sections. On the contrary, after being preheated, PSJO90 properties such as kinematic viscosity, surface tension, and density seem to be similar to those of DF. Thus, PSJO90 cavitation-based atomization must have occured similar to DF. Cavitation pattern or the formation of bubbles inside the injector hole takes place when the hydrostatic pressure in an area of the fuel flow is decreased below the vapor pressure. Normally, cavitation bubbles can reach the exit of the injector hole and are near the wall of the injector hole because the pressure inside the bubbles is much lower than that around the emerging fuel-jet (Fig. 4c). Because of the above-mentioned pressure differences, cavitation bubbles are collapsed gradually due to the internal fuel-jet turbulence. Thanks to the implosion of cavitation bubbles, jet atomization is enhanced. In this case, the basic assumption is that cavitation bubbles are either burst at the periphery or collapsed due to the turbulence velocity inside the liquid.

As reported by Som et al. (2010) and Shervani-Tabar et al. (2012), the cavitation time-scale depends much on the fuel vapor pressure and density as well as injector configuration. An inverse proportional relationship between the cavitation time scale and fuel vapor pressure and density has been shown in those studies. In a recent study, the utilization of the cavitation mechanism as an injection strategy to improve fuel-air mixture quality was investigated (Hoang and Le, 2019). As shown in Figure 3, PSJO90 and DF were effectively turned into vapor after leaving the injector. These results demonstrated the remarkable effects of fue properties on its spray characteristics. These effects were also reported by previous publications (Mohan et al., 2013; Shameer and Ramesh, 2018).

It is evident that the combination of high injection-pressure and small diameters of injector holes may provide better characteristics including spray characteristics, air entrainment, fuel-air mixing, as well as the homogeneity of the mixture with reasonable fuel-air equivalence ratios. There would be thus fewer over-rich fuel regions. In a study by Hoang and Le (2019), the important effects of injector configuration and diameter of the injector hole on fuel spray and atomization were reported. They showed that a transfigured injector hole (e.g., much deposit) could cause negative impacts reducing spray angles and particle sizes and consequently, increasing spray tip penetrations. As a result, the interwoven interaction between spray characteristics and injector configuration should be taken into account seriously. In better words, any factors affecting injector configuration, could also affect fuel spray characteristics.

\subsection{Deposits in the injector hole}

After $300 \mathrm{~h}$ of engine operation using DF, SJO30, and PSJO90, the diesel engine was partly dissembled to screen the level of accumulated deposits in the injector holes using SEM. The SEM micrograph of the clean injector hole (at $0 \mathrm{~h}$ ) is shown in Figure 5a while the injector holes after $300 \mathrm{~h}$ of operation for DF, SJO30, and PSJO90 are presented in Figures $5 \mathrm{~b}, 5 \mathrm{c}$, and $5 \mathrm{~d}$, respectively.

It can be clearly seen from Figure 5 that deposit accumulation in the injector hole in case of using SJO30 was much higher than when the engine was fueled by DF and PSJO90. Higher temperatures around the injector tips are considered as notable characteristics of advanced diesel injection systems which may also result in the formation of stubborn deposits in the area of the injector tips (Hoang and Le, 2019). Moreover, deposits formation was increased substantially by using PSJO90 in comparison with DF. Compared to the deposits associated with the utilization of SJO30 and PSJO90 (Figs. 5c and 5d, respectively), the deposits formed in response to the usage of DF (Fig. 5b) were uniformly formed with a thick layer of carbon. The dimension of the injector hole for DF was around $0.004 \mathrm{~mm}$ smaller than that of the clean injector hole, revealing that the accumulation of deposits around the injector tips would not significantly interfere with the injector holes.

Normally, under high temperatures, the decomposition of hydrocarbons or compounds containing carbon, the main compositional element of fuels, and/or polymerization or condensation process or conversion of hydrocarbon components into larger polycyclic aromatic hydrocarbons (PAHs) (which are then nucleated and grown), are considered as two mechanisms leading to the formation of carbonaceous deposits. As discussed earlier in Section 4.1, higher kinematic viscosity, density, and surface tension of SJO30 resulted in lower volatility of this fuel, consequently leading to poor atomization and the formation of fuel-rich mixture with larger-sized fuel droplets during the fuel injection process into the combustion chamber. Fuel droplet size and fuel concentration could affect ignition delay strongly. Fuels with higher kinematic viscosity values are associated with longer ignition delays as it takes them more time to turn into vapor. Owing to this reason, deposit formation rate for fuels with higher kinematic viscosity values tends to increase. Furthermore, vegetable 

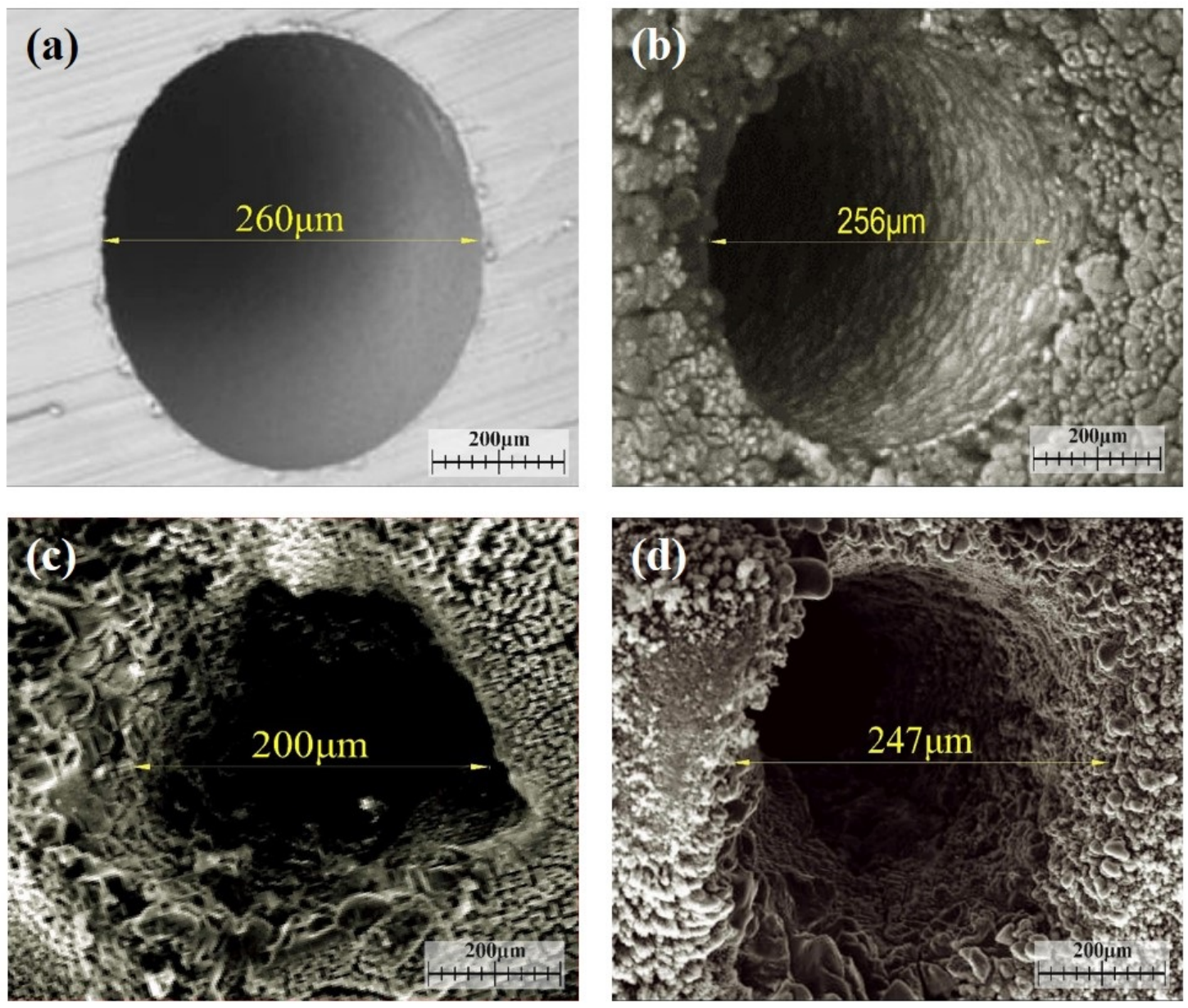

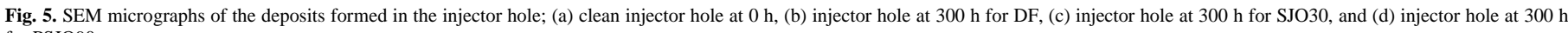
for PSJO90.

oils are usually decomposed at higher temperatures, hence, the possibility of vegetable oils decomposition or conversion into sticky and unburned components during the ignition delay period should be considered as a cause of deposits generation in injector tips and holes.

Deposits formed through the combustion of vegetable oils and their derivatives, i.e., biodiesel, include volatile substances, high boiling point substances, oxidizing substances, carbonization substances, and residual ashes (Liaquat et al., 2013). In addition, the higher iodine value of vegetable oils (resulting from the presence of unsaturated compounds) compared to DF, is also believed to be a contributing parameter to a longer ignition delay (Hoang and Pham, 2018b). Therefore, it could be concluded that there is a cohere relationship between fuel properties and spray characteristics and consequently deposit formation in the injector. The small cone angle and high penetration length for Jatropha oil may have increased the focusing degree of fuel droplets per certain area, reduced the evaporation rate, and fuel injection velocity. These could imply that many fuel droplets must have come into contact with the hightemperature air in the combustion chamber, forming deposits. Low injection velocity could result in retaining a proportion of the vegetable oil volume in the injector. Moreover, high fuel concentration, the molecular mass of fatty acids contained in the vegetable oil, and the sticky properties of the oil are the main factors causing increased deposit formation in the injector as well as an increased metal concentration in the deposits due to the corrosive nature of fatty acids to metallic parts.

In addition, it can be clearly seen from the data presented in Table 1 that the flash point temperature of Jatropha oil was above 3 times higher than that of DF, whereas cetane number and heat content of Jatropha oil were lower than those of DF. The above-mentioned characteristics of Jatropha oil at room temperature $\left(30{ }^{\circ} \mathrm{C}\right)$ could be considered as the essence of increasing deposits formation in the injector in the diesel engine running on SJO30. On the contrary, deposit formation in the injector of the diesel engine fueled with PSJO90 (Fig. 5d) tended to decrease compared to SJO30, the degree of accumulated deposits in case of PSJO90 was insignificantly higher than that of DF. In another word, the diameter of the injector hole was decreased by $0.013 \mathrm{~mm}$ for PSJO90 while this value stood at $0.06 \mathrm{~mm}$ for SJO30. Besides, the diameter of the injector hole for SJO30 seemed to be disfigured. Based on the diameter of the injector hole, deposits formation using SJO30 was around 5 times and 15 times higher than when using PSJP90 and DF, respectively. The reduction in deposits accumulation for PSJO90 could be ascrobed to the fact that the density, kinematic viscosity, and surface tension of PSJO90 were similar to those of DF, although the molecular mass of PSJO was unchanged in response to preheating and was higher than that of DF. Similar results were also reported by other studies (Birgel et al., 2012; Hazar and Sevinc, 2019).

\subsection{Combustion characteristics}

As presented earlier in Section 4.1, the cavitation and turbulence mechanisms in the process of fuel primary breakup are associated with increased atomization rate, resulting in smaller penetration lengths. This 
implies that evaporation, the formation of a homogeneous fuel-air mixture, ignition and combustion processes are strongly affected by the primary breakup. In an experimental study by Higgins and Siebers (2001), the influences of the length of liquid $\left(\mathrm{L}_{\mathrm{l}}\right)$ and flame lift-off $\left(\mathrm{L}_{\mathrm{f}}\right)$ on the primary breakup and the combustion process were investigated. Accordingly, the interaction between $\mathrm{L}_{\mathrm{l}}$ and $\mathrm{L}_{\mathrm{f}}$ plays an important role in combustion efficiency, thermal efficiency, and emissions of diesel engines. For $\mathrm{L}_{\mathrm{f}}>\mathrm{L}_{\mathrm{l}}$, the fuel evaporation process terminates before the beginning of the combustion process and the establishment of fuel-rich flames is induced. In this case, fuel would be burnt incompletely leading to an increase in deposits formation and emissions due to lack of oxygen. On the other hand, a two-way coupling between vaporization and combustion occurs in case of $\mathrm{L}_{\mathrm{f}}<\mathrm{L}_{\mathrm{l}}$, therefore, the temperature of the combustion process decreases because of the enhancement of fuel evaporation under high temperatures. The reduction of flame temperature is reported as the main reason resulting in moving the flame stabilization location to downstream, and an increase in $\mathrm{L}_{\mathrm{f}}$ can be clearly seen. Obviously, along with the increase in pressure and temperature in the combustion chamber, the density of the ambient increases, causing a decrease in the injection velocity of liquid fuel at the injector exit. Due to this reason, the flame stabilization location moves to upstream, leading to an increase in deposits formation at low-temperature regions (Som et al., 2010). Besides, oxygen concentration could also strongly affect flame structure and combustion efficiency, and it thus could affect thermal efficiency and emissions. Consequently, the engine could achieve high thermal efficiency and low emissions with high volatility of fuel, sufficient oxygen component, proper fuel properties, and neither rich nor lean mixtures.

\subsubsection{Thermal efficiency}

Thermal efficiency is a parameter characterizing the effectiveness of the combustion process. Normally, a complete combustion is associated with a high thermal efficiency. Based on Equation 1, thermal efficiency is critically dependent on BSFC. The thermal efficiency values of the investigated diesel engine fueled with SJO30 and PSJO90 are compared to that of DF in Figure 6.

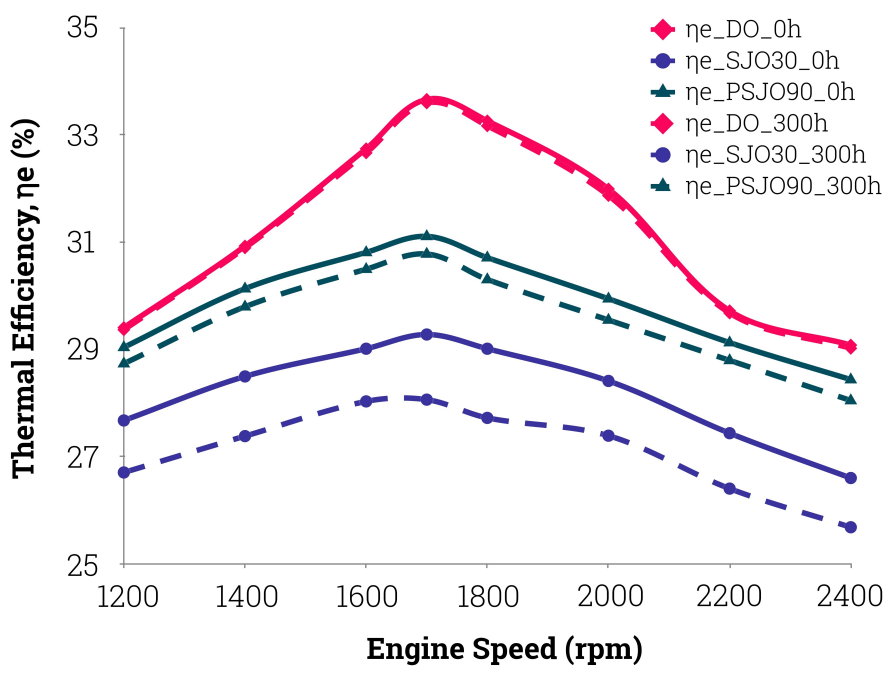

Fig. 6. The thermal efficiency of the engine running on different fuels at $0 \mathrm{~h}$ and after $300 \mathrm{~h}$ of engine operation.

Based on the data presented in Figure 6, thermal efficiency was generally reduced for all the invesigated fuels. However, this reduction was insignificant for DF after $300 \mathrm{~h}$ of engine operation, i.e., only $0.38 \%$ compared to $0 \mathrm{~h}$. While the maximum reduction of thermal efficiency for PSJO90 after $300 \mathrm{~h}$ of operation stood at $1.37 \%$ vs. $4.41 \%$ for SJO30. The reduction of thermal efficiency could be ascribed to the increase in BSFC and reduction of combustion efficiency. Although Jatropha oil was preheated to a suitable temperature to obtain similar spray characteristics, its lower heat content and cetane number compared to those of DF could be considered as the main reasons contributing to the lower thermal efficiency recorded. Due to this reason, more fuel was injected into the combustion chamber to maintain the power, as a result, BSFC for Jatropha oil was higher than that of DF. On the other hand, deposits built-up inside the injector nozzle, on/outside the injector tip led to adverse and negative impacts on the BSFC and the performance of diesel engine. The deposits formed mostly inside the injector hole was the main reason resulting in the reduction of fuel flow rate (Hoang and Le, 2019). These findings were in agreement with those presented in Figure 5 revealing reductions in the hole diameter of the injector. Meanwhile, fuel injection pressure was maintained, resulting in a reduction in cone angle and an increase in penetration length of the fuel spray. As a result, fuel concentration was limitted to a small area on the piston crown and fuel was burned incompletely in the combustion chamber. The reduction of thermal efficiency could be considered as the main factor causing power losses because after all, thermal efficiency and engine power are the final outputs characterizing the combustion process. Similar results on thermal efficiency were reported in the studies conducted by Ozsezen (2012) and Acharya et al. (2014b).

\subsubsection{Exhaust emissions}

The combustion process in diesel engines occurs at the temperature when fuel-air mixture is ignited under suitable conditions in the combustion chamber. The aim of the combustion process shown in Figure 7 is to decompose the hydrocarbon components of the fuel and convert them into complete combustion products. Hydrocarbon peroxide radicals $(-\mathrm{ROOH})$ are considered as the initial products of fuel decomposition. These radicals are generated by breaking down the alkane molecules through the dehydrogenation process. In the subsequent chemical reactions, radicals such as $\mathrm{H} \bullet, \mathrm{O} \bullet$, and $\mathrm{OH} \bullet$ are produced in the disintegration process of fuels. Subsequently, some light hydrocarbons including alkenes $\left(\mathrm{C}_{2} \mathrm{H}_{4}, \mathrm{C}_{3} \mathrm{H}_{6}\right)$ and alkines $\left(\mathrm{C}_{2} \mathrm{H}_{2}\right)$ along with aldehydes are formed by the chain propagators. Following the oxidation process, intermediate substances are converted into final products. Normally, around $10 \%$ of the heat content is discharged for the formation of aldehyde substances while around $40 \%$ of the heat content is discharged in the oxidation reactions to genertae $\mathrm{CO}$ and the oxidation process of $\mathrm{CO}$ into $\mathrm{CO}_{2}$ releases the reamaining heat content of approximately $45 \%$.

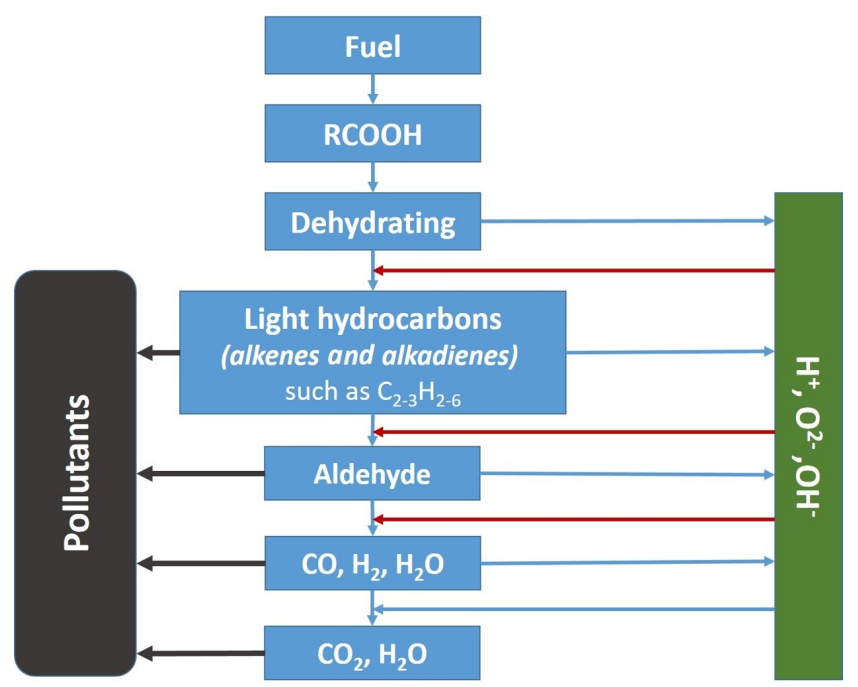

Fig. 7. Schematic presentation of fuel combustion and emissions formation.

As shown in Figure 7, it can be seen that oxygenated fuels or added oxygen in the combustion process could facilitate the complete oxidation 


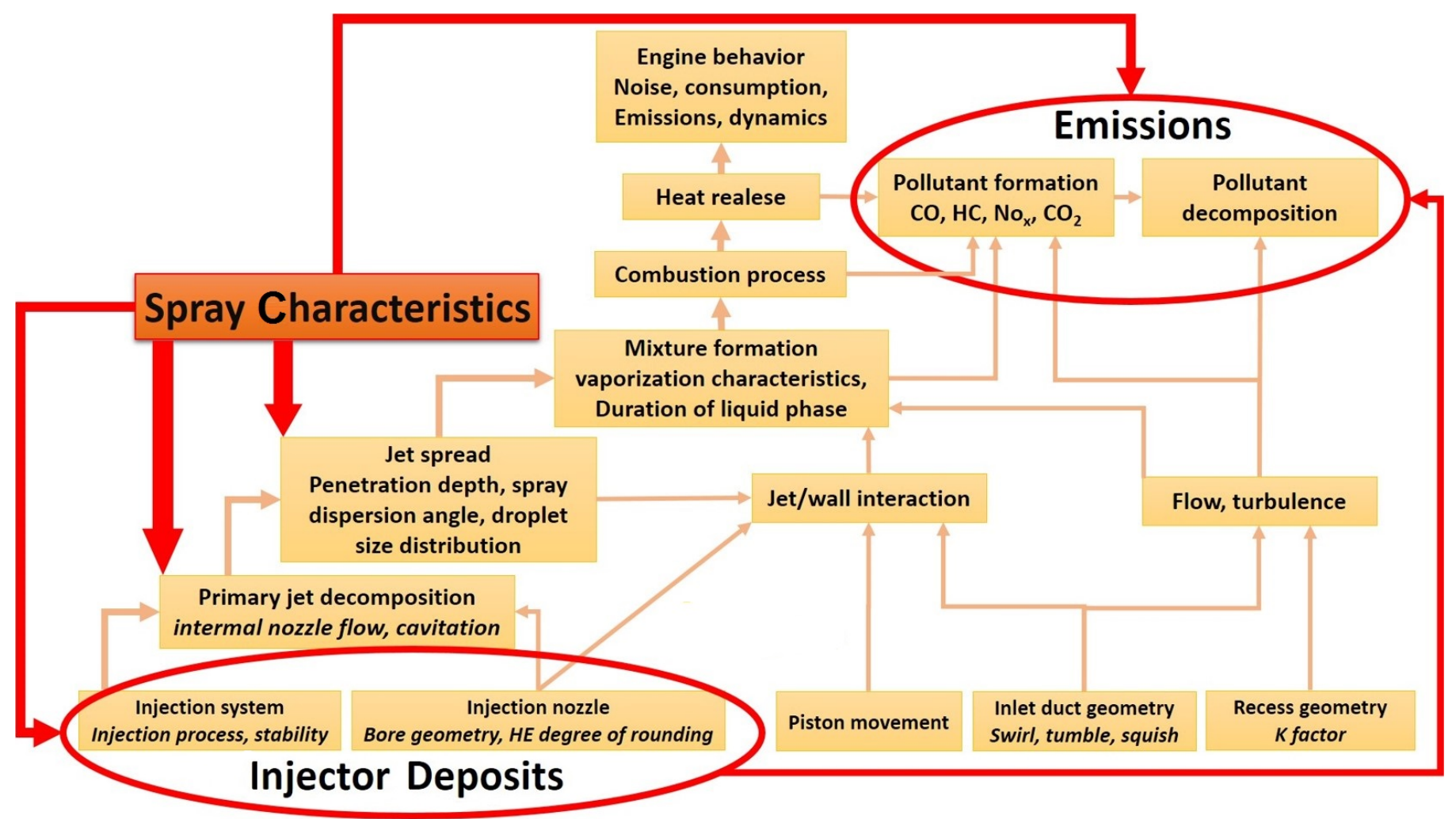

Fig. 8. Schematic presentation of the relationship among spray characteristics, breakup mechanism, and emissions formation.

and conversion $\mathrm{CO}$ into $\mathrm{CO}_{2}$. As a result, much of the released energy could be used for improving and enhancing thermal efficiency and engine power as well as for reducing pollutants (Chen et al., 2019). The relationship among spray characteristics, breakup mechanism, and emissions formation is illustrated in Figure 8 .

Obviously, changes in emission characteristics, as shown Figure 8, highly depend on the combustion process of engines. Complete combustion generates more complete products such as $\mathrm{CO}_{2}$ than incomplete products such as $\mathrm{HC}$, $\mathrm{CO}$; while, NOx emissions are strongly affected by the temperatures of the combustion process. In the combustion process, the fuel mass burnt in the premixed phase and mixing controlled phase is strongly affected by not only injector configuration and diesel engine design, but also by fuel type and operating conditions (such as engine speed and engine load). For example, since it is difficult to break fatty acids with long carbon-chains and double bonds or aromatic hydrocarbons, higher concentrations of these compounds lead to longer ignition delays.

On the other hand, when fuels are injected fast enough to mix with compressed air homogeneously and completely before occurring the autoignition process, the all mixture fuel-air burns rapidly in the premixed phase, creating a large change in the parameters characterizing the combustion efficiency such as high peak pressure, thermal efficiency, and emissions (Hoang et al., 2019). The emission characteristics of the investigated diesel engine fueled with SJO30, PSJO90, and DF are shown in Figures 9a-d. As show, there was an overall increasing tendency for $\mathrm{HC}, \mathrm{CO}$, and smoke emissions and a decreasing tendency for $\mathrm{NO}_{\mathrm{x}}$ emissions $v s$. engine speed.

Carbon monoxide (CO) is produced in the exhaust of diesel engines in response to fuel-rich mixtures and lack of oxygen to convert all the carbon component into carbon dioxide $\left(\mathrm{CO}_{2}\right)$. The equivalence ratio of fuel-air is considered as the most important parameter directly affecting $\mathrm{CO}$ emissions. $\mathrm{CO}$ emission can be described based on the chemical reactions involved in the conversion $\mathrm{C}-\mathrm{O}-\mathrm{H}$ systems into $\mathrm{CO}$ through the interaction of $\mathrm{C}-\mathrm{O}-\mathrm{H}$ systems with $\mathrm{H} \bullet, \mathrm{O} \bullet$, and $\mathrm{OH} \bullet$ (Hoang et al., 2019). As presented in Figure 9a, it can be observed that $\mathrm{CO}$ emissions associated with $\mathrm{SJO} 30$ combustion were $77.57 \%$ and $26.36 \%$ higher than those of DF and PSJO90 at $0 \mathrm{~h}$. Interestingly, after $300 \mathrm{~h}$ of engine operation, changes in $\mathrm{CO}$ emissions for DF were insignificant while CO emissions associated with PSJO90 and SJO30 were considerably increased by $43.28 \%$ and $111.21 \%$, respectively, compared to the values recorded at $0 \mathrm{~h}$. The results of $\mathrm{CO}$ emissions were in agreement with those of thermal efficiency because a large amount of energy was released in the process of $\mathrm{CO}$ conversion into $\mathrm{CO}_{2}$.

Unburned hydrocarbon (HC) emissions are considered as the result of the presence of unburned fuel in the exhaust gas components. There are around 10-20 major species and 100-200 minor species in hydrocarbon chain-based fuels. Most of the exhaust hydrocarbons detected are originated from the parent fuel but some of them are found with altered structures due to clearly-unknown chemical reactions in the cylinder of diesel engines. As a result, a reduction of thermal efficiency and an increase in pollutants are associated with an increase in $\mathrm{HC}$ emissions. Normally, HC emissions reach their highest values when diesel engines are started or are warmed up because of decreased vaporization and mixing rate as well as fuel oxidation under these conditions. It was reported by Cheng et al. (1993) that there are six mechanisms involved in increasing $\mathrm{HC}$ emissions including: (i) crevices, (ii) oil layers, (iii) deposits (fuel trapped or retained in the injector hole at the end of injection process), (iv) fuel and mixture (fuel-air mixtures so rich or so lean that cannot be ignited), (v) cylinder wall flame quenching, and (vi) the leakage of exhaust valve. Besides the amount of $\mathrm{HC}$ emissions caused by the crevice mechanism, fuel properties, lubricating oil degradation, and deposits have been shown to cause the largest amounts of total HC emissions.

As a result of the porous nature of the deposits as well as the smaller size of their pores than the quenching distance, flames are incapable of burning 

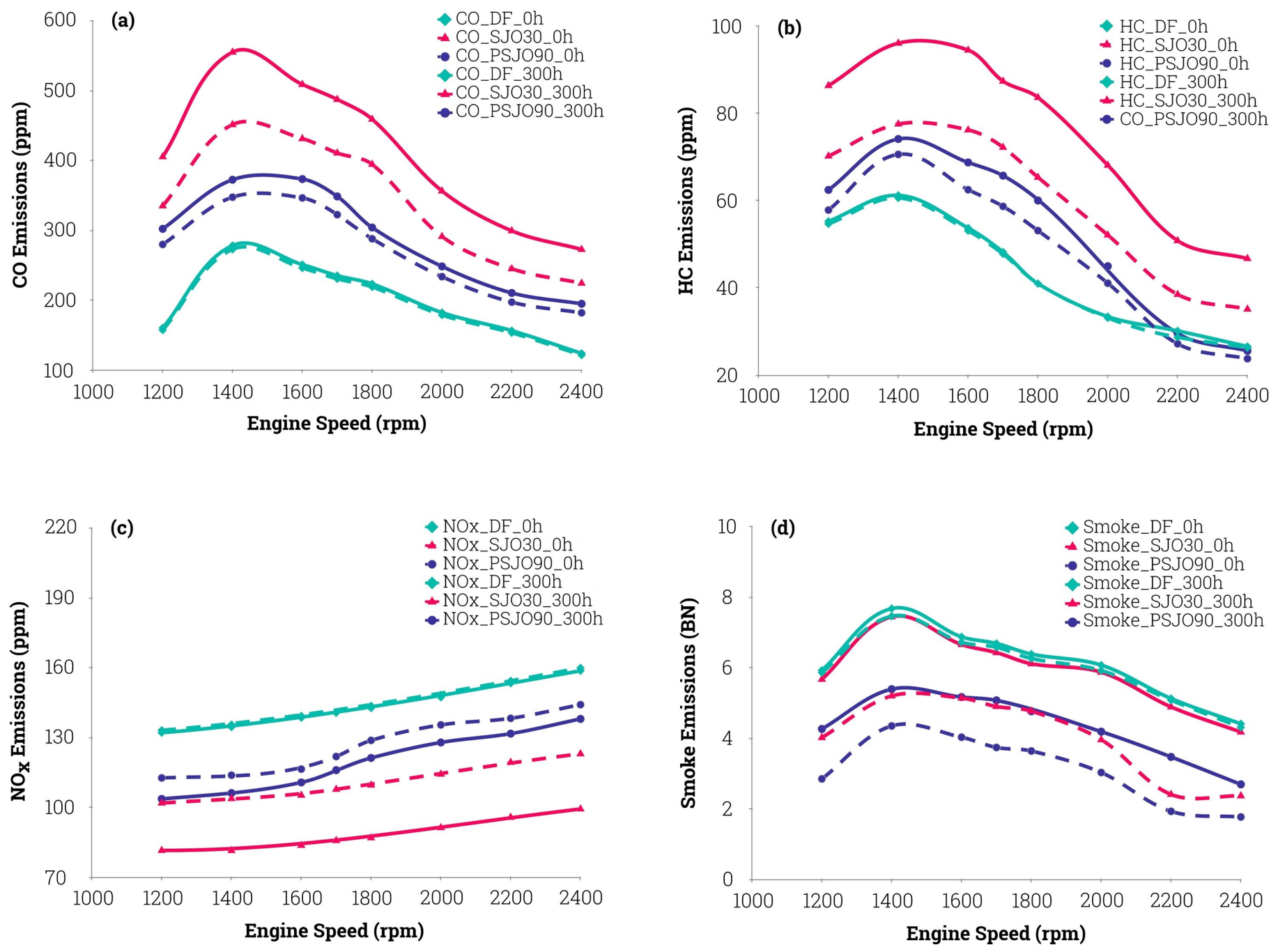

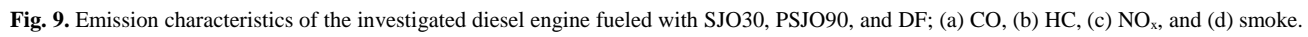

the residual fuel-air mixture (Hoang and Pham, 2018a). This residual fuel-air mixture is believed to come out of the pores in the expansion duration and blowdown duration. On the other hand, the reduction of cylinder gas temperatures and the consequent incomplete combustion reactions are among the reasons considered for increases in $\mathrm{HC}$ emissions from diesel engines. Figure 9b presents $\mathrm{HC}$ emissions of the tested fuels. At $0 \mathrm{~h}, \mathrm{HC}$ emissions of the investigated diesel engine running on $\mathrm{SJO} 30$ was $41.98 \%$ and $26.95 \%$ higher than that of DF and PSJO90, respectively. After $300 \mathrm{~h}$ of engine operation, $\mathrm{HC}$ emissions of the diesel engine running on SJO30 and PSJO90 tended to increase significantly, while the $\mathrm{HC}$ emission associated with DF was mostly unchanged. $\mathrm{HC}$ emissions for $\mathrm{SJO} 30$ after $300 \mathrm{~h}$ of engine operation were $77.85 \%$ and $48.98 \%$ higher than those of DF and PSJO90, respectively. This could be attributed to the higher fuel mass injected due to the higher density of SJO30. Moreover, the dispersal area of SJO30 fuel spray was limitted, and the penetration length was high due to its higher kinematic viscosity resulting in larger fuel droplets and consequently, in lower evaporation rate as well as the formation of a heterogeneous fuel-air mixture. In better words, when using SJO30, a fuel-rich mixture was produced and oxygen was insufficient to support a thorough burning process leading to increased $\mathrm{CO}$ and $\mathrm{HC}$ emissions. Nevertheless, as discussed earlier, the large amount of deposits formed in the injector after $300 \mathrm{~h}$ of engine operation and the resultant transfiguration of the injector and injector clogging could be regarded the main cause of the huge changes observed in $\mathrm{CO}$ and $\mathrm{HC}$ emissions of the engine fueled with SJO30. It should be noted that by using PSJO90 some fuel properties and fuel spray characteristics were much improved. However, some unfavorable fuel properties, i.e., lower cetane number, lower heating value, and lower volatility compared to DF, could be highlighted as the reasons contributing to its higher $\mathrm{CO}$ and $\mathrm{HC}$ emission than those of DF. The findings of the present study on $\mathrm{CO}$ and $\mathrm{HC}$ emissions were in agreement with those of the other studies published previously (Yilmaz and Morton, 2011; Acharya et al., 2014a).

Nitrogen oxide $\left(\mathrm{NO}_{\mathrm{x}}\right)$ emissions are formed through the reaction of atomic oxygen and nitrogen under high temperature conditions existing in the combustion chamber. $\mathrm{NO}_{\mathrm{x}}$ emissions produced during combustion depend largely on temperature and engine load. Normally, during the start of engine or warm-up process, $\mathrm{NO}_{\mathrm{x}}$ emissions are relatively low (Hoang et al., 2018c). There are three reaction mechanisms used to explain the formation and production of $\mathrm{NO}_{\mathrm{x}}$ during combustion, i.e., the Zeldovich mechanism (also known as thermal mechanism), the Fenimore (also known as prompt mechanism), and the intermediate mechanism for $\mathrm{N}_{2} \mathrm{O}$ (nitrous 
oxide) formation. Nevertheless, the Zeldovich mechanism may be considered as the most significant one for internal combustion engines. After all, $\mathrm{NO}_{\mathrm{x}}$ emissions are influenced by fuel properties, fuel-air mixture (fuel-rich or fuellean mixture), engine operation conditions, and combustion chamber design. Figure $9 \mathrm{c}$ shows the trend of $\mathrm{NO}_{\mathrm{x}}$ emissions which were inversely proportional to those of $\mathrm{HC}$ and $\mathrm{CO}$ emissions. More specifically, $\mathrm{NO}_{\mathrm{x}}$ emission tended to increase by increase engine speed. Based on the data presented in Figure 9c, it can be clearly comprehended that $\mathrm{NO}_{\mathrm{x}}$ emissions of SJO30 were $23.42 \%$ and $12.31 \%$ lower than those of DF and PSJO90 at $0 \mathrm{~h}$, respectively. This observation could be explained by the effects of fuel properties and fuel-air mixture on $\mathrm{NO}_{\mathrm{x}}$ emissions. Obviously, DF with higher cetane number, higher heat content, higher volatility, and lower density led to higher combustion tempreture and consequently higher $\mathrm{NO}_{\mathrm{x}}$ emissions compared to $\mathrm{SJO} 30$ and PSJO90. Similarly, the lower density of PSJO90 (vs. SJO30) led to less fuel mass injected and the formation of a more homogeneous fuel-air mixture. This in turn resulted in higher combustion temperatures for PSJO90 than for SJO30, leading to higher $\mathrm{NO}_{\mathrm{x}}$ emissions. The results of $\mathrm{NO}_{\mathrm{x}}$ emissions were in agreement with those of thermal efficiency as well as $\mathrm{HC}$ and $\mathrm{CO}$ emissions. After $300 \mathrm{~h}$ of operation, $\mathrm{NO}_{\mathrm{x}}$ emissions for $\mathrm{SJO} 30$ and PSJO90 reduced remarkably by $20.30 \%$ and $5.61 \%$, respectively, in comparison with the $0 \mathrm{~h}$; while, $\mathrm{NO}_{\mathrm{x}}$ emissions associated with $\mathrm{DF}$ were nearly unchanged. The reduction of $\mathrm{NO}_{\mathrm{x}}$ emissions $v s$. time of engine operation, could be ascribed to decreased thermal efficiency and increased amounts of deposits, resulting in reduced combustion temperatures in the combustion chamber as previously reported by Rakopoulos et al. (2015) as well.

Smoke is generated in diesel engines due to heterogeneous combustion in diesel engines. Commonly, reduction in $\mathrm{NO}_{\mathrm{x}}$ emissions is attributed to increases in PM and smoke emissions (Johnson et al., 2010). This is because reduction in $\mathrm{NO}_{\mathrm{x}}$ emission is ascribed to decreases in the temperature of diffuse flames in the combustion chamber, resulting in a reduction of the amount of oxidized soot (Wang and Chung, 2016). Based on the data on smoke emissions depicted in Figure 9d, at $0 \mathrm{~h}$, smoke emissions for DF were higher than those of SJO30 and PSJO90, which could be explained by the favorable impact of the oxygen contained in Jatropha oil (approx. 11\%). In fact, smoke emissions of PSJO90 at $0 \mathrm{~h}$ were $48.48 \%$ and $29.96 \%$ lower than those of DF and SJO30, respectively. However, after $300 \mathrm{~h}$ of engine operation using SJO30, due to the huge amounts of deposits formed in the injector holes, some fuel might be trapped in the injector holes, leading to significant increases in smoke emissions. A similar trend was also observed for PSJO 90 after $300 \mathrm{~h}$ of engine operation (Figure 9d). More specifically, smoke emissions for PSJO90 after $300 \mathrm{~h}$ of engine operation were $36.35 \%$ and $29.29 \%$ lower than those of DF and SJO30, respectively. These findings confirmed the remarkable impacts of oxygenated fuels in reducing smoke emissions. The results obatined in relation to smoke emissions were in agreement with previous reports such as that of Hoang and Nguyen (2017).

\section{Conclusions}

In this experimental study, the influences of DF, SJO30, and PSJO90 on spray characteristics, deposit formation in the injector, and emission characteristics of a high-speed 4-stroke diesel engine were investigated. The spray characteristics of SJO30 were much different from those of PSJO90 and DF. After $300 \mathrm{~h}$ of the endurance test, the amounts of deposits formed in the injector hole using SJO30 were considerably higher compared to PSJO90 and $\mathrm{DF}$, transfiguring the injector hole. This consequently led to increased BSFC and reduced brake thermal efficiency for SJO30 compared to the other fuels investigated. On the other hand, $\mathrm{SJO} 30$ was associated with significant reductions in NOx emissions (14.69-20.30\%) but large increases in CO emissions (26.36-77.57\%), HC emissions (48.98-77.85\%), and smoke (58.43$131.71 \%$ ). In conclusion, SJO30 cannot be recommended for long-term use in diesel engines while preheating or in better words, PSJO90 may only be considered as an alternative fuel in the short term.

\section{References}

[1] Acharya, S.K., Swain, R.K., Mohanty, M.K., 2014. Emission analysis of using preheated Karanja and Kusum oil. Energy Sources Part A. 36(12), 1358-1365

[2] Acharya, S.K., Swain, R.K., Mohanty, M.K., Mishra, A.K., 2014. Preheated and blended Karanja oil as diesel engine fuel. Energy Sources
Part A. 36(12), 1325-1334

[3] Barker, J., Richard, P., Snape, C., Meredith, W., 2011. Diesel injector deposits-an issue that has evolved with engine technology. SAE Technical Paper. 2011-01-1923.

[4] Baumgarten, C., 2006. Mixture formation in internal combustion engines. Springer Sci. Business Media.

[5] Birgel, A., Ladommatos, N., Aleiferis, P., Milovanovic, N., Lacey, P., Richards, P., 2012. Investigations on deposit formation in the holes of diesel injector nozzles. SAE Int. J. Fuels Lubr. 5(1), 123 131

[6] Cazarolli, J.C., de Quadros, P.D., Bücker, F., Santiago, M.R.F., Piatnicki, C.M.S., Peralba, M.D.C.R., Cavalcanti, E.H.D.S., Bento, F.M., 2016. Microbial growth in Acrocomia aculeata pulp oil Jatropha curcas oil, and their respective biodiesels under simulated storage conditions. Biofuel Res. J. 3(4), 514-520.

[7] Chen, H., Su, X., He, J., Xie, B., 2019. Investigation on combustion and emission characteristics of a common rail diesel engine fueled with diesel/n-pentanol/methanol blends. Energy. 167, 297-311.

[8] Cheng, W.K., Hamrin, D., Heywood, J.B., Hochgreb, S., Min, K. Norris, M., 1993. An overview of hydrocarbon emissions mechanisms in spark-ignition engines. SAE Trans. 102, 1207-1207.

[9] D'Alessandro, B., Bidini, G., Zampilli, M., Laranci, P., Bartocci, P. Fantozzi, F., 2016. Straight and waste vegetable oil in engines: review and experimental measurement of emissions, fuel consumption and injector fouling on a turbocharged commercial engine. Fuel. 182, 198-209

[10] Demirbas, A., 2017. Tomorrow's biofuels: goals and hopes. Energy Sources Part A. 39(7), 673-679.

[11] Deshmukh, D., Mohan, A.M., Anand, T.N.C., Ravikrishna, R.V., 2012. Spray characterization of straight vegetable oils at high injection pressures. Fuel. 97, 879-883.

[12] Hazar, H., Sevinc, H., 2019. Investigation of the effects of preheated linseed oil on performance and exhaust emission at a coated diesel engine. Renewable Energy. 130, 961-967.

[13] Higgins, B., Siebers, D.L., 2001. Measurement of the flame lift-off location on DI diesel sprays using $\mathrm{OH}$ chemiluminescence. SAE Technical Paper 2001-01-0918

[14] Hoang, A.T., Nguyen, V.T., 2017. Emission characteristics of a diesel engine fuelled with preheated vegetable oil and biodiesel. Philippine J. Sci. 146(4), 475-482.

[15] Hoang, A.T., 2018a. Prediction of the density and viscosity of biodiesel and the influence of biodiesel properties on a diesel engine fuel supply system. J. Mar. Eng. Technol. 1-3.

[16] Hoang, A.T., 2018b. Waste heat recovery from diesel engines based on organic rankine cycle. Appl. Energy. 231, 138-166

[17] Hoang, A.T., Noor, M.M., Pham, X.D., 2018. Comparative analysis on performance and emission characteristic of diesel engine fueled with heated coconut oil and diesel fuel. Int. J. Automot. Mech. Eng. 15(1), 5110-5125.

[18] Hoang, A.T., Pham, V.V., 2018a. A review on fuels used for marine diesel engines. J. Mech. Eng. Res. Dev. 41(4), 22-32.

[19] Hoang, A.T., Pham, V.V., 2018b. Impact of jatropha oil on engine performance, emission characteristics, deposit formation, and lubricating oil degradation. Combust. Sci. Technol. 1-16.

[20] Hoang, A.T., Pham, M.T., 2018c. Influences of heating temperatures on physical properties, spray characteristics of bio-oils and fuel supply system of a conventional diesel engine. Int. J. Adv. Sci. Eng. Inf. Technol. 8(5), 2231-2240.

[21] Hoang, A.T., Le, A.T., 2019. A review on deposit formation in the injector of diesel engines running on biodiesel. Energy Sources Part A. 41(5), 584-599

[22] Hoang, A.T., Pham, V.V., 2019. A study of emission characteristic, deposits, and lubrication oil degradation of a diesel engine running on preheated vegetable oil and diesel oil. Energy Sources Part A. 41(5), 611-625

[23] Hoang, A.T., Tran, Q.V., Al-Tawaha, A.R.M.S., Pham, V.V. Nguyen, X.P., 2019. Comparative analysis on performance and emission characteristics of an in-Vietnam popular 4-stroke motorcycle engine running on biogasoline and mineral gasoline. Renewable Energy Focus. 28, 47-55. 
[24] Johnson, K.G., Mollenhauer, K., Tschöke, H., 2010. Handbook of diesel engines. Springer Sci. Bus. Media.

[25] Kumar, M.V., Babu, A.V., Kumar, P.R., Reddy, S.S., 2018. Experimental investigation of the combustion characteristics of Mahua oil biodiesel-diesel blend using a DI diesel engine modified with EGR and nozzle hole orifice diameter. Biofuel Res. J. 5(3), 863-871.

[26] Lefebvre, A.H., McDonell, V.G., 2017. Atomization sprays. CRC press.

[27] Li, H., Lea-Langton, A., Biller, P., Andrews, G.E., Hadavi, S., Charlton, A., Richards, P., 2010. Effect of multifunctional fuel additive package on fuel injector deposit, combustion and emissions using pure rape seed oil for a DI diesel. SAE Int. J. Fuels Lubr. 2(2), 54-65.

[28] Liaquat, A.M., Masjuki, H.H., Kalam, M.A., Fazal, M.A., Khan, A.F., Fayaz, H., Varman, M., 2013. Impact of palm biodiesel blend on injector deposit formation. Appl. Energy. 111, 882-893.

[29] Littlejohns, J., Rehmann, L., Murdy, R., Oo, A., Neill, S., 2018. Current state and future prospects for liquid biofuels in Canada. Biofuel Res. J. $5(1), 759-779$

[30] Manchanda, T., Tyagi, R., Sharma, D.K., 2018. Comparison of fuel characteristics of green (renewable) diesel with biodiesel obtainable from algal oil and vegetable oil. Energy Sources Part A. 40(1), 54-59.

[31] Mohan, B., Yang, W., kiang Chou, S., 2013. Fuel injection strategies for performance improvement and emissions reduction in compression ignition engines-a review. Renew. Sust. Energy Rev. 28, 664-676.

[32] Olarte, M.V., Zacher, A.H., Padmaperuma, A.B., Burton, S.D., Job, H.M., Lemmon, T.L., Swita, M.S., Rotness, L.J., Neuenschwander, G.N., Frye, J.G., 2016. Stabilization of softwood-derived pyrolysis oils for continuous bio-oil hydroprocessing. Top. Catal. 59(1), 55-64.

[33] Ozsezen, A.N., 2012. Using preheated crude sunflower oil as a fuel in a diesel engine. Energy Sources Part A. 34(6), 508-518.

[34] Pipitone, E., Costanza, A., 2018. An experimental investigation on the long-term compatibility of preheated crude palm oil in a large compression ignition diesel engine. Biofuel Res. J. 5(4), 900-908.

[35] Pham, M.T., Hoang, A.T., Le, A.T., Al-Tawaha, A., Dong, V.H., Le, V.V., 2018. Measurement and prediction of the density and viscosity of biodiesel blends. Int. J. Technol. 9(5), 1015-1026.

[36] Rajaeifar, M.A., Tabatabaei, M., Abdi, R., Latifi, A.M., Saberi, F., Askari, M., Zenouzi, A., Ghorbani, M., 2017. Attributional and consequential environmental assessment of using waste cooking oil-and poultry fat-based biodiesel blends in urban buses: a real-world operation condition study. Biofuel Res. J. 4(3), 638-653.
[37] Rakopoulos, D.C., Rakopoulos, C.D., Giakoumis, E.G., 2015. Impact of properties of vegetable oil, bio-diesel, ethanol and $n$ butanol on the combustion and emissions of turbocharged HDDI diesel engine operating under steady and transient conditions. Fuel. $156,1-19$.

[38] Rakopoulos, D.C., Rakopoulos, C.D., Giakoumis, E.G, Papagiannakis, R.G., Kyritsis, D.C., 2014. Influence of properties of various common bio-fuels on the combustion and emission characteristics of high-speed DI (direct injection) diesel engine: vegetable oil, bio-diesel, ethanol, $n$-butanol, diethyl ether. Energy. 73, 354-366.

[39] Reddy, M.S., Sharma, N., Agarwal, A.K., 2016. Effect of straight vegetable oil blends and biodiesel blends on wear of mechanical fuel injection equipment of a constant speed diesel engine. Renewable Energy. 99, 1008-1018.

[40] Rogers, K.A., Zheng, Y., 2016. Selective deoxygenation of biomassderived bio-oils within hydrogen-modest environments: a review and new insights. ChemSusChem. 9(14), 1750-1772.

[41] Salehi Jouzani, G., Sharafi, R., Soheilivand, S., 2018. Fueling the future; plant genetic engineering for sustainable biodiesel production. Biofuel Res. J. 5(3), 829-845.

[42] Satyanarayana, M., Muraleedharan, C., 2012. Experimental studies on performance and emission characteristics of neat preheated vegetable oils in a di diesel engine. Energy Sources Part A. 34(18), 1710-1722.

[43] Shameer, P.M., Ramesh, K., 2018. Assessment on the consequences of injection timing and injection pressure on combustion characteristics of sustainable biodiesel fuelled engine. Renew. Sust. Energy Rev. 81, 45-61.

[44] Shervani-Tabar, M.T., Parsa, S., Ghorbani, M., 2012. Numerical study on the effect of the cavitation phenomenon on the characteristics of fuel spray. Math. Comput. Modell. 56(5-6), $105-$ 117.

[45] Som, S., Aggarwal, S.K., 2010. Effects of primary breakup modeling on spray and combustion characteristics of compression ignition engines. Combust. Flame. 157(6), 1179-1193.

[46] Wang, Y., Chung, S.H., 2016. Formation of soot in counterflow diffusion flames with carbon dioxide dilution. Combust. Sci. Technol. 188(4-5), 805-817.

[47] Yilmaz, N., Morton, B., 2011. Effects of preheating vegetable oils on performance and emission characteristics of two diesel engines. Biomass Bioenergy. 35(5), 2028-2033. 